\title{
Effect of Sugarcane Bagasse Ash and Lime Stone Fines on the Mechanical Properties of Concrete
}

\author{
Naraindas Bheel \\ Department of Civil Technology \\ H.C.S.T \\ Hyderabad, Pakistan \\ naraindas04@gmail.com \\ Noor Muhammad Talpur \\ Department of Civil Technology \\ H.C.S.T \\ Hyderabad, Pakistan \\ mirnoor2018@gmail.com
}

\author{
Abdul Samad Memon \\ Department of Civil Technology \\ H.C.S.T \\ Hyderabad, Pakistan \\ samad.memon105@gmail.com \\ Sher Muhammad Talpur \\ Department of Civil Technology \\ H.C.S.T \\ Hyderabad, Pakistan \\ shermohd168@gmail.com
}

\author{
Imdad Ali Khaskheli \\ Department of Civil Technology \\ H.C.S.T \\ Hyderabad, Pakistan \\ imdadali961@gmail.com \\ Muhammad Awais Khanzada
Department of Civil Technology
H.C.S.T
Hyderabad, Pakistan
awais.khanzada145@gmail.com
}

\begin{abstract}
Cement production releases huge amounts of carbon dioxide having a significant impact on the environment while also having huge energy consumption demands. In addition, the disposal and recovery of natural concrete components can lead to environmental degradation. The use of waste in concrete not only reduces cement production, but it also reduces energy consumption. The aim of this study is to evaluate the properties of fresh and hardened concrete by partially replacing cement with sugarcane bagasse ash (SCBA) and limestone fines (LSF). In this investigation work the cement was replaced with SCBA ash and LSF by $0 \%(0 \%$ SCBA+ $0 \%$ LSF $), 5 \%(2.5 \%$ SCBA $+2.5 \%$ LSF), $10 \%(5 \%$ SCBA+ $5 \%$ LSF $), 15 \%(7.5 \%$ SCBA+ $7.5 \%$ LSF) and $20 \%(10 \%$ SCBA+ $10 \%$ LSF $)$ by weight of cement. In this regard, a total of 60 samples of concrete specimens were made with mix proportion of $1: 1.5: 3$ with 0.56 water-cement ratio. Cube specimens were tested for compressive strength and cylindrical specimens were used for determining splitting tensile strength at 7 and 28 days respectively. The optimum result displayed that the crushing strength and split tensile strength increased by $10.33 \%$ and $10.10 \%$ while using $5 \%$ SCBA+ $5 \%$ LSF as a substitute for cement in concrete after the $28^{\text {th }}$ day. The slump value of concrete declined as the content of SCBA and LSF increased.
\end{abstract}

Keywords-limestone fines; sugarcane bagasse ash; cement replacement; enhance strength and reduce environmental issues

\section{INTRODUCTION}

Concrete is a man-made construction material, which is most commonly used for the construction of various civil engineering structures [1-3]. Ordinary Portland cement (OPC) concrete is used in numerous structural applications and it is favorable for normal construction projects. However, due to some of its limitations, certain requirements have been difficult to satisfy especially in terms of strength and durability regarding complex structures. The need for the development of high-strength and high-performance concrete has extensively increased in order to meet the requirements for advanced and complex structures [4]. The development of High-Strength Concrete (HSC) requires a large amount of cement and the production of cement is considered as the most energyintensive component for the production of concrete [5]. $\mathrm{CO}_{2}$ emissions during the production of cement are an environmental concern. It is a well-known fact that approximately one ton of $\mathrm{CO}_{2}$ is released into the environment through one-ton production of OPC cement. Moreover, cement manufacturing is responsible for $5 \%$ to $7 \%$ of $\mathrm{CO}_{2}$ emissions from industrial sources [6]. Without compromising the performance of the concrete structures, the use of Portland cement needs to be reduced in order to reduce $\mathrm{CO}_{2}$ emissions related to cement production while the sustainability of construction needs to be taken into consideration [7-9]. Partial substitutions of cement by a combination of cement replacing materials (CRMs) are advantageous not only from the economic point of view but also for their mechanical and microstructural characteristics [10]. The use of CRMs into concrete has gained popularity with emphasis on increasing the service life of concrete structures [11]. Many CRMs are commercially available and can be used in concrete. Some of the most common materials are sugarcane bagasse ash (SCBA) [12, 13], limestone fines (LSF), rice husk ash (RHA) [14-16], silica fume (SF), etc. $[17,18]$. In this experimental investigation, the combined influence of SCBA and LSF used as cement replacement materials in cement concrete was determined.

SCBA is a sugar mill by-product found after burning bagasse, which in turn was originated after the sugar extraction from sugarcane. It has been tested for volcanic ash properties and improvements have been found in mortar and concrete, such as in crushing strength, durability, and water resistance in certain proportions [19]. LSF were collected from Hyderabad and they can be used either as a cementitious material or as fine aggregates in concrete mix [20-22]. There are several studies 
conducted on the strength development of concrete containing SCBA and LSF. Authors in [23] determined the influence of SCBA on the hardened concrete. Concrete samples were prepared with 1:2:4 mix ratio and were tested for compressive and split tensile strength at 28 days. The test results advocated that the crushing and indirect tensile strength were enhanced by $7.90 \%$ and $14 \%$ at $10 \%$. Authors in [24] studied the effects of LSF content on concrete's compressive strength and durability. They reported that increasing the amount of LSF in concrete enhances strength and decreases permeability. LSF concrete having $0.40 \mathrm{w} / \mathrm{b}$ ratio performed better as compared to 0.50 and $0.60 \mathrm{w} / \mathrm{b}$ ratio $\mathrm{LSF}$ concrete regarding strength development. The porosity and pore size of concrete were significantly decreased after 28 days. Authors in [25] observed that the crushing and bending strength and permeability related properties were improved by using LSF in concrete.

In the available literature there are a limited number of studies available on the individual and combined effects of SCBA and LSF as cement replacing material in concrete. Several types of mineral admixtures are used in concrete but their effects on concrete properties with binary and ternary blends are not investigated in satisfying depth. The main aim of this paper is to investigate the combined effect of SCBA and LSF with cement on fresh and hardened concrete. Since the compressive strength of concrete is an important parameter, and all other properties of concrete are judged on the basis of its compressive strength. In addition, statistical assessment on compressive strength of concrete using RSM has been performed in order to investigate the effectiveness of each material on the basis of its compressive strength.

\section{RESEARCH METHODOLOGY}

This research study aimed to determine the fresh, physical and hardening properties of concrete by using of $0 \%(0 \%$ SCBA+ 0\% LSF), 5\% (2.5\% SCBA+ 2.5\% LSF), 10\% (5\% $\mathrm{SCBA}+5 \% \mathrm{LSF}), 15 \%(7.5 \% \mathrm{SCBA}+7.5 \% \mathrm{LSF})$ and $20 \%$ $(10 \% \mathrm{SCBA}+10 \% \mathrm{LSF})$ cement replacement materials in concrete. A total of 60 concrete samples of $1: 1.5: 3 \mathrm{mix}$ proportions were prepared (30 cylinders and 30 cubes) with 0.56 water/cement ratio and were cured for 7 and 28 days.

TABLE I. CONCRETE MIXES

\begin{tabular}{|c|c|c|c|c|}
\hline ID & $\begin{array}{c}\text { SCBA + LSF } \\
(\mathbf{\%})\end{array}$ & $\begin{array}{c}\text { F.A \& CA } \\
(\mathbf{\%})\end{array}$ & $\begin{array}{c}\text { Cement } \\
(\mathbf{\%})\end{array}$ & $\begin{array}{c}\text { Water-cement } \\
\text { ratio (\%) }\end{array}$ \\
\hline 01 & $0 \%+0 \%$ & 100 & 100 & 0.56 \\
\hline 02 & $2.5 \%+2.5 \%$ & 100 & 95 & 0.56 \\
\hline 03 & $5 \%+5 \%$ & 100 & 90 & 0.56 \\
\hline 04 & $7.5 \%+7.5 \%$ & 100 & 85 & 0.56 \\
\hline 05 & $10 \%+10 \%$ & 100 & 80 & 0.56 \\
\hline
\end{tabular}

Mix ratio 1:1.5:3

The variables cement (binder), coarse aggregates, fine aggregates, and water were considered. SCBA and LSF were used as CRMs and the concrete samples were tested on an UTM. In this study, concrete cubes $(100 \mathrm{~mm} \times 100 \mathrm{~mm} \times 100 \mathrm{~mm})$ ware cast and tested for compressive strength. Similarly, cylinders $(200 \mathrm{~mm} \times 100 \mathrm{~mm})$ were tested for splitting tensile strength. Moreover, the concrete specimens were tested for water absorption and concrete density after 28 days. Three concrete samples were cast for each ratio, and the mean of the samples was considered as the ultimate result. The study was conducted in a laboratory of the Department of Civil Technology, H.C.S.T Hyderabad, Sindh, Pakistan [26, 27].

\section{MATERIALS USED}

\section{A. Cement}

In this investigational study, OPC was utilized with $33 \%$ normal consistency, and initial and final setting time of $46 \mathrm{~min}$ and $160 \mathrm{~min}$ respectively.

\section{B. Fine and Coarse Aggregates}

Hill sand was used as fine aggregates that passed through \#4 sieves and crushed stones having $20 \mathrm{~mm}$ in size were used as coarse aggregates. These aggregates were collected locally in the region of Hyderabad.

\section{Limestone Fines (LSF)}

The LSF were collected from Hyderabad. After collecting, they were sieved through $\# 300$ sieves to obtain fine powder form and then they were utilized as cementitious material in concrete mixes.

\section{Sugarcane Bagasse Ash (SCBA)}

SCBA was collected from Matiari Sugar Mill. After collecting, it was dried under the atmosphere and the dried ash was sieved through \#300 sieves to obtain the desired ash. This desired ash was utilized as cement replacement in concrete.

\section{E. Water}

Drinking water was used.

\section{RESULTS AND DISCUSSION}

\section{A. Slump Test}

Slump test was studied based on slump losses using a standard slump cone in accordance with ASTM C 143-05. At $0 \%$ SCBA and $0 \%$ LSF, the maximum concrete slump is $65 \mathrm{~mm}$, and at $10 \%$ SCBA and $10 \%$ LSF, the minimum slump of fresh concrete is $29 \mathrm{~mm}$. The slump value reduced as the amount of SCBA and LSF increased as shown in Figure 1.

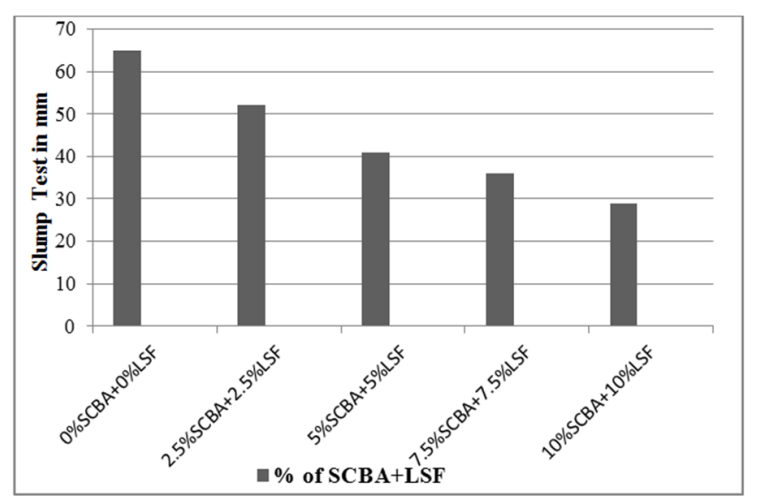

Fig. 1. Slump test results

\section{B. Density of Concrete}

The concrete samples were used to analyze the density of concrete with addition of several ratios of SCBA and LSF by 
weight of cement on the $28^{\text {th }}$ day. The maximum value of $2380 \mathrm{~kg} / \mathrm{m}^{3}$ was noted at $0 \% \mathrm{SCBA}+0 \% \mathrm{LSF}$ and the minimum value of $2290 \mathrm{~kg} / \mathrm{m}^{3}$ at $10 \% \mathrm{SCBA}+10 \% \mathrm{LSF}$ after 28 days. The density of concrete reduced as the SCBA and LSF content increased as shown in Figure 2.

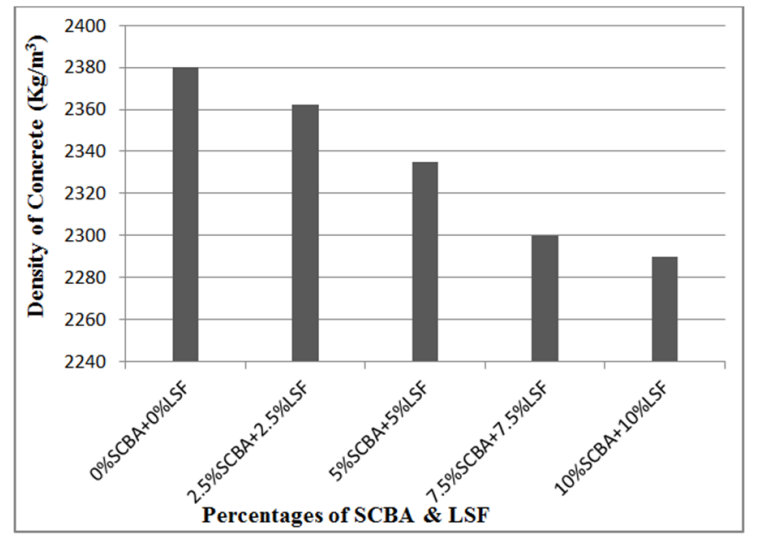

Fig. 2. Density of concrete

\section{Water Absorption}

The concrete samples were used to analyze the water absorption of concrete with addition of several ratios of SCBA and LSF by weight of cement at the $28^{\text {th }}$ day. It was recorded maximum $(4.30 \%)$ at $10 \% \mathrm{SCBA}+10 \% \mathrm{LSF}$ and minimum $2.50 \%$ at $0 \%$ SCBA $+0 \%$ LSF after 28 days. The water absorption of concrete augmented with increasing content of SCBA and LSF as shown in Figure 3.

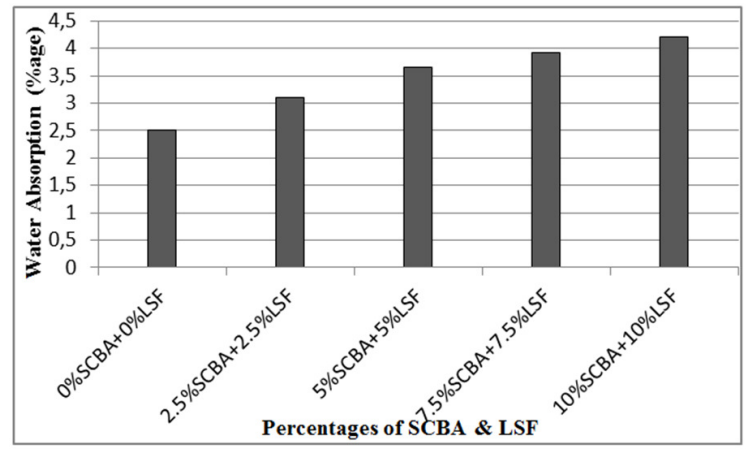

Fig. 3. Water absorption of concrete

\section{Compressive Strength}

The cubical samples were checked for analyzing compressive strength of concrete. The optimum crushing strength was increased to $8.96 \%$ and $10.33 \%$ at $5 \% \mathrm{SCBA}+$ $5 \%$ LSF and it was decreased by $9.80 \%$ and $6.40 \%$ at $10 \%$ SCBA $+10 \%$ LSF after 7 days and 28 days respectively as shown in Figure 4.

\section{E. Split Tensile Strength}

The cylindrical samples were checked for split tensile strength of concrete with several percentages of LSF and SCBA. The optimum indirect tensile strength was augmented by $8.20 \%$ and $10.10 \%$ at $5 \%$ SCBA $+5 \%$ LSF and was reduced by $9.84 \%$ and $4.04 \%$ at $10 \%$ SCBA $+10 \%$ LSF after 7 and 28 days respectively as displayed in Figure 5.

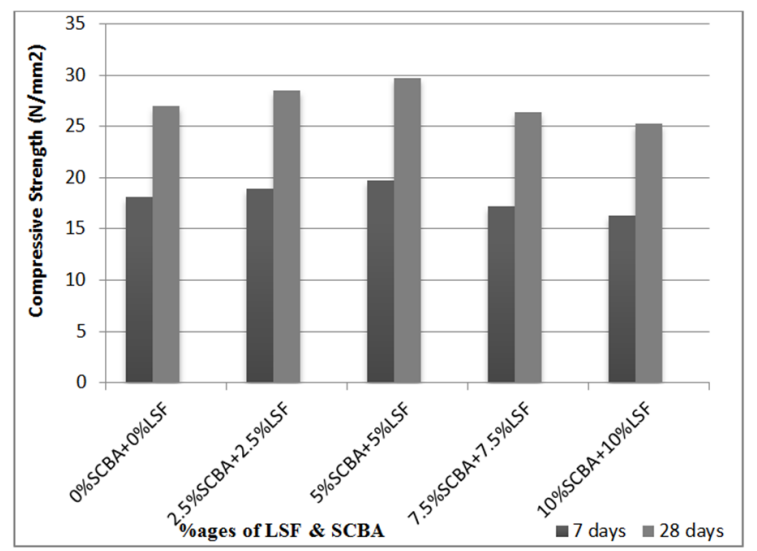

Fig. 4. Compressive strength of concrete

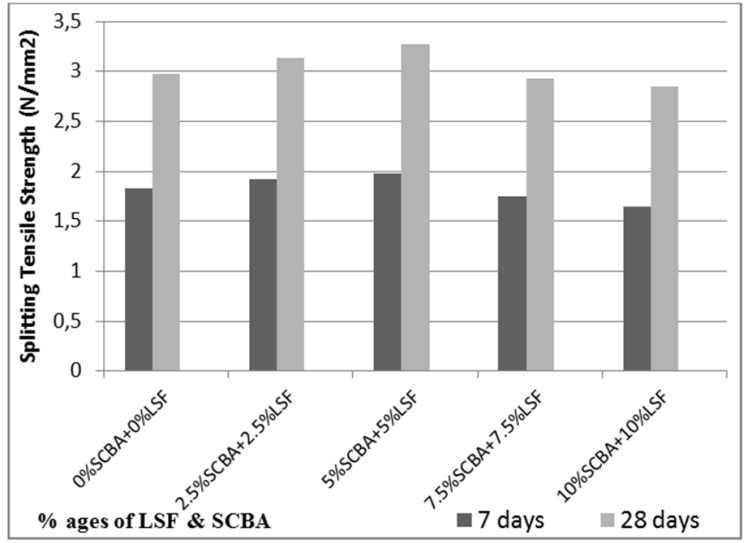

Fig. 5. Split tensile strength of concrete

\section{CONCLUSIONS}

The basic aim of this study was the utilization of SCBA and LSF as cement replacements in concrete and to determine their effect on the fresh and hardened concrete properties. From this research study, the following conclusions can be drawn:

- At $0 \%$ SCBA and $0 \% \mathrm{LSF}$, the concrete slump is maximum $(65 \mathrm{~mm})$, and at $10 \% \mathrm{SCBA}$ and $10 \% \mathrm{LSF}$, the slump of fresh concrete is minimum $(29 \mathrm{~mm})$. Moreover, the slump value reduced as the amount of SCBA and LSF increased.

- The density of concrete was maximum $\left(2380 \mathrm{~kg} / \mathrm{m}^{3}\right)$ at $0 \%$ $\mathrm{SCBA}+0 \%$ LSF and minimum $\left(2290 \mathrm{~kg} / \mathrm{m}^{3}\right)$ at $10 \%$ SCBA $+10 \%$ LSF after 28 days. The density of concrete reduced as the SCBA and LSF content increased.

- Water absorption of concrete was maximum (4.30\%) at $10 \% \mathrm{SCBA}+10 \% \mathrm{LSF}$ and minimum $(2.50 \%)$ at $0 \%$ $\mathrm{SCBA}+0 \% \mathrm{LSF}$ after 28 days. The water absorption of concrete increased as the amount of SCBA and LSF increased. 
- The optimum crushing strength increased by $8.96 \%$ and $10.33 \%$ at $5 \%$ SCBA $+5 \%$ LSF and decreased by $9.80 \%$ and $6.40 \%$ at $10 \%$ SCBA $+10 \%$ LSF after 7 and 28 days respectively.

- The optimum indirect tensile strength increased by $8.20 \%$ and $10.10 \%$ at $5 \%$ SCBA $+5 \%$ LSF and reduced by $9.84 \%$ and $4.04 \%$ at $10 \%$ SCBA $+10 \%$ LSF after 7 and 28 days respectively.

\section{REFERENCES}

[1] M. Uysal, V. Akyuncu, "Durability performance of concrete incorporating Class $\mathrm{F}$ and Class $\mathrm{C}$ fly ashes", Construction and Building Materials, Vol. 34, pp. 170-178, 2012

[2] N. Bheel, R. A. Abbasi, S. Sohu, S. A. Abbasi, A. W. Abro, Z. H. Shaikh, "Effect of tile powder used as a cementitious material on the mechanical properties of concrete", Engineering, Technology \& Applied Science Research, Vol. 9, No. 5, pp. 4596-4599, 2019

[3] N. D. Bheel, F. A. Memon, S. L. Meghwar, A. W. Abro, I. A. Shar, "Millet husk ash as environmental friendly material in cement concrete", 5th International Conference on Energy, Environment and Sustainable Development, Jamshoro, Pakistan, November 14-16, 2018

[4] S. W. M. Supit, F. U. A. Shaikh, "Durability properties of high volume fly ash concrete containing nano-silica", Materials and Structures, Vol. 48, pp. 2431-2445, 2015

[5] N. Bheel, K. A. Kalhoro, T. A. Memon, Z. U. Z. Lashari, M. A. Soomro, U. A. Memon, "Use of marble powder and tile powder as cementitious materials in concrete", Engineering, Technology \& Applied Science Research, Vol. 10, No. 2, pp. 5448-5451, 2020

[6] N. Bheel, M. A. Jokhio, J. A. Abbasi, H. B. Lashari, M. I. Qureshi, A. S. Qureshi, "Rice husk ash and fly ash effects on the mechanical properties of concrete", Engineering, Technology \& Applied Science Research, Vol. 10, No. 2, pp. 5402-5405, 2020

[7] L. J. Hanle, K. R. Jayaraman, J. S. Smith, " $\mathrm{CO}_{2}$ emissions profile of the US cement industry", Washington DC: Environmental Protection Agency, available at: https://www3.epa.gov/ttnchie1/ conference/ei13/ghg/hanle.pdf, 2004

[8] F. Ma, A. Sha, P. Yang, Y. Huang, "The greenhouse gas emission from Portland cement concrete pavement construction in China", International Journal of Environmental Research and Public Health, Vol. 13, No. 7, Article ID 632, 2016

[9] P. C. Aitcin, High performance concrete, CRC Press, 1998

[10] K. A. Gruber, T. Ramlochan, A. Boddy, R. D. Hooton, M. D. A. Thomas, "Increasing concrete durability with high-reactivity metakaolin", Cement and Concrete Composites, Vol. 23, No. 6, pp. 479484, 2001

[11] R. Kumar, A. Y. B. M. Yaseen, N. Shafiq, A. Jalal, "Influence of metakaolin, fly ash and nano silica on mechanical and durability properties of concrete", Key Engineering Materials, Vol. 744, pp. 8-14, 2017

[12] N. D. Bheel, S. K. Meghwar, R. A. Abbasi, I. A. Ghunio, Z. H. Shaikh, "Use of sugarcane bagasse ash as cement replacement materials in concrete", International Conference on Sustainable Development in Civil Engineering, Jamshoro, Pakistan, December 5-7, 2019

[13] A. A. Dayo, A. Kumar, A. Raja, N. Bheel, A. W. Abro, Z. H. Shaikh, "Effect of sugarcane bagasse ash as fine aggregates on the flexural strength of concrete", International Conference on Sustainable Development in Civil Engineering, Jamshoro, Pakistan, December 5-7, 2019

[14] N. Bheel, A. W. Abro, I. A. Shar, A. A. Dayo, S. Shaikh, Z. H. Shaikh, "Use of rice husk ash as cementitious material in concrete", Engineering, Technology \& Applied Science Research, Vol. 9, No. 3, pp. 4209-4212, 2019

[15] N. Bheel, S. L. Meghwar, S. A. Abbasi, L. C. Marwari, J. A. Mugeri, R. A. Abbasi, "Effect of rice husk ash and water-cement ratio on strength of concrete", Civil Engineering Journal, Vol. 4, No. 10, pp. 2373-2382, 2018
[16] N. Bheel, S. L. Meghwar, S. Sohu, A. R. Khoso, A. Kumar, Z. H. Shaikh, "Experimental study on recycled concrete aggregates with rice husk ash as partial cement replacement", Civil Engineering Journal, Vol. 4, No. 10, pp. 2305-2314, 2018

[17] S. Ghosal, S. C. Moulik, "Use of rice husk ash as partial replacement with cement in concrete: A review", International Journal of Engineering Research, Vol. 4, No. 9, pp. 506-509, 2015

[18] Z. H. Shaikh, A. Kumar, M. A. Kerio, N. Bheel, A. A. Dayo, A. W. Abro, "Investigation on selected properties of concrete blended with maize cob ash", $10^{\text {th }}$ International Civil Engineering Conference, Karachi, Pakistan, February 23-24, 2019

[19] L. G. Li, A. K. H. Kwan, "Adding limestone fines as cementitious paste replacement to improve tensile strength, stiffness and durability of concrete", Cement and Concrete Composites, Vol. 60, pp. 17-24, 2015

[20] S. Kenai, B. Menadi, A. Attar, J. Khatib, "Effect of crushed limestone fines on strength of mortar and durability of concrete", International Conference on Construction and Building Technology, Kuala Lumpur, Malaysia, June 16-20, 2008

[21] I. A. Shar, F. A. Memon, N. Bheel, Z. H. Shaikh, A. A. Dayo, "Use of wheat straw ash as cement replacement material in the concrete", International Conference on Sustainable Development in Civil Engineering, Jamshoro, Pakistan, December 5-7, 2019

[22] A. M. Diab, I. A. Mohamed, A. A. Aliabdo, "Impact of organic carbon on hardened properties and durability of limestone cement concrete", Construction and Building Materials, Vol. 102, pp. 688-698, 2016

[23] A. A. Dayo, A. Kumar, A. Raja, N. Bheel, Z. H. Shaikh, "Use of sugarcane bagasse ash as a fine aggregate in cement concrete", Engineering Science and Technology International Research Journal, Vol. 3, No. 3, pp. 8-11, 2019

[24] J. J. Chen, A. K. H. Kwan, Y. Jiang, “Adding limestone fines as cement paste replacement to reduce water permeability and sorptivity of concrete", Construction and Building Materials, Vol. 56, pp. 87-93, 2014

[25] C. Aquino, M. Inoue, H. Miura, M. Mizuta, T. Okamoto, "The effects of limestone aggregate on concrete properties", Construction and Building Materials, Vol. 24, No. 12, pp. 2363-2368, 2010

[26] N. D. Bheel, S. A. Abbasi, S. L. Meghwar, F. A. Shaikh, "Effect of human hair as fibers in cement concrete", International Conference on Sustainable Development in Civil Engineering, Jamshoro, Pakistan, November 23-25, 2017

[27] A. N. Khan, N. D. Bheel, M. Ahmed, R. A. Abbasi, S. Sohu, "Use of styrene butadiene rubber (SBR) polymer in cement concrete", Indian Journal of Science and Technology, Vol. 13, No. 5, pp. 606-616, 2020 